\title{
Role of Bacterial OmpA and Host Cytoskeleton in the Invasion of Human Intestinal Epithelial Cells by Enterobacter sakazakii
}

\author{
MANOJ KUMAR MOHAN NAIR AND KUMAR VENKITANARAYANAN \\ Department of Animal Science, University of Connecticut, Storrs, Connecticut 06269
}

\begin{abstract}
Enterobacter sakazakii is an emerging pathogen in neonates and infants. Interactions of E. sakazakii with intestinal epithelium could be vital in the pathogenesis of enteric infections and in its systemic dissemination. The present study investigated the interaction of E. sakazakii with human intestinal epithelial (INT407) cells and the role of bacterial outer membrane protein A (OmpA) and host cytoskeleton in these interactions. E. sakazakii invaded INT407 cells with moderate efficiency. An $o m p A^{-}$mutant of E. sakazakii was significantly attenuated in its invasiveness, and complementation restored the invasive phenotype significantly. Drugs acting on host cell microfilaments (MF) and microtubules (MT) significantly inhibited bacterial invasion. Localization of both microfilaments (MF) and microtubules (MT) was observed in INT407 cells following $E$. sakazakii infection. The results suggest that E. sakazakii invasion of INT407 cells involves participation of both MF and MT and bacterial OmpA plays a critical role in invasion. (Pediatr Res 62: 664-669, 2007)
\end{abstract}

$\mathrm{E}$ nterobacter sakazakii is an opportunistic pathogen that causes an often fatal form of meningitis, meningoencephalitis, necrotizing enterocolitis, and sepsis in neonates and infants, with a case fatality rate of $14 \%(1-3)$. Besides the high rate of mortality, the brain infections due to E. sakazakii often lead to permanent impairments in mental and physical capabilities in surviving patients (4). Contaminated powdered infant formula represents the only known source of infection in neonates (3-6). A recent outbreak of neonatal infection caused by $E$. sakazakii (7) and the recall of E. sakazakiicontaminated infant formula preparations (8) in the Unites States have stimulated a renewed research interest on this pathogen.

Currently, very little information is available on the virulence factors of E. sakazakii and its pathogenic mechanisms. Some strains of E. sakazakii have been shown to produce an enterotoxin that is lethal in suckling mice and produce cytopathic effects in cell lines (9), however, no clear association between enterotoxin production and pathogenesis has been established. The most probable route of entry of E. sakazakii is the oral route since feeding of contaminated infant formula has been established as the only known link to infection in neonates. Therefore, the most likely primary colonization site of this pathogen is the intestinal tract, and stool colonization of E. sakazakii without overt signs of infection has been reported

Received March 14, 2007; accepted July 10, 2007.

Correspondence: Kumar Venkitanarayanan, Ph.D., Department of Animal Science, Unit-4040, 3636, Horsebarn Hill Road Extension, Storrs, CT 06269; e-mail: Kumar.venkitanarayanan@uconn.edu

Supported by the United States Department of Agriculture (USDA-CONS 00764).
(7). To cause extraintestinal infections such as sepsis and meningitis, the pathogen has to break through the intestinal mucosa, gain access to the bloodstream, and survive the host defense mechanisms before gaining entry into the CNS. Fibronectin, a major glycoprotein component of the extracellular matrix of eukaryotic tissue (10) serves as an adherence target in the internalization process of many bacterial pathogens, including Staphylococcus aureus, Streptococcus pyogenus, and Neisseria gonorrhoeae (11-13). Our studies have identified that the outer membrane protein A (OmpA) of E. sakazakii binds fibronectin and facilitates the invasion of brain endothelial cells (unpublished results). This study reports the interaction of $E$. sakazakii with human intestinal epithelial cells and the role of its OmpA and host cytoskeleton in these interactions.

\section{MATERIALS AND METHODS}

This study was approved by the University of Connecticut Institutional Biosafety Committee.

Bacterial strains, plasmids, and culture conditions. The bacterial strains and plasmids used in this study are listed in Table 1. Escherichia coli JM109 was used as host for plasmids. E. sakazakii and E. coli were grown in Luria-Bertani (LB) broth at $37^{\circ} \mathrm{C}$ with shaking. E. coli strains harboring the various plasmids were grown on LB agar and antibiotics were added when required at the following levels: ampicillin $(100 \mu \mathrm{g} / \mathrm{mL})$, chloramphenicol (cm; $25 \mu \mathrm{g} / \mathrm{mL})$, streptomycin $(100 \mu \mathrm{g} / \mathrm{mL})$, and rifampin $(100 \mu \mathrm{g} / \mathrm{mL})$.

ompA mutation and complementation. Genomic and plasmid DNA were isolated using the AquaPure Genomic DNA isolation kit (Bio-Rad, Hercules, CA) and QIAprep spin miniprep kit (QIAGEN, Valencia, CA), respectively. Restriction endonuclease digestions, ligations, and transformations were performed as per standard protocols (14). Primers (OmpAORF-F2, 5' GATAGTGGTGAATGAACGG-3' and OmpAORF-R, 5'-GAGCGTAAAGAGAAGTATG-3') designed based on ompA sequence of E. sakazakii 51329 (15) (GenBank Accession number DQ000206) were used to amplify the ompA ORF with flanking sequences from E. sakazakii strain ES4586. The PCR product was cloned in pGEM-T Easy (Promega, Madison, WI) yielding pGompA. An internal 867-bp NruI/BglII fragment of ompA was replaced with a 958-bp chloramphenicol acetyl transferase cassette (amplified from pACYC184 using primers CAT2F-BamHI, 5'-CGCGGATCCGCGTATCACTTATTCAGGCGTAGC-3' and CAT1R-SmaI, 5'-CATGGTACCCGGGCCCTAAATACCTGTGACGGAAGAT- $3^{\prime}$ and digested with BamH1 and

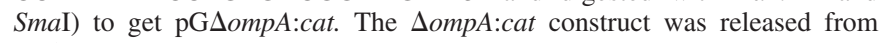
pG $\Delta$ ompA:cat by NotI digestion and ligated to NotI site on the suicide vector pKNG101 (16). The plasmid, pK $\Delta$ ompA:cat was transformed into E. coli SM10 $\lambda$ pir and mobilized to ES4586 by conjugation. Rifampin- and cmresistant colonies were selected for ompA deletion on LB plates with 5\% sucrose. The sucrose-resistant colonies were screened for $\mathrm{cm}$-resistance and streptomycin-sensitivity and were confirmed for mutation of the ompA gene by PCR, sequencing and Southern hybridization.

Abbreviations: cm, chloramphenicol; MF, microfilaments; MOI, multiplicity of infection; MT, microtubules; OMP, outer membrane protein; OmpA, Outer membrane protein A 
Table 1. Bacterial strains and plasmids used in this study

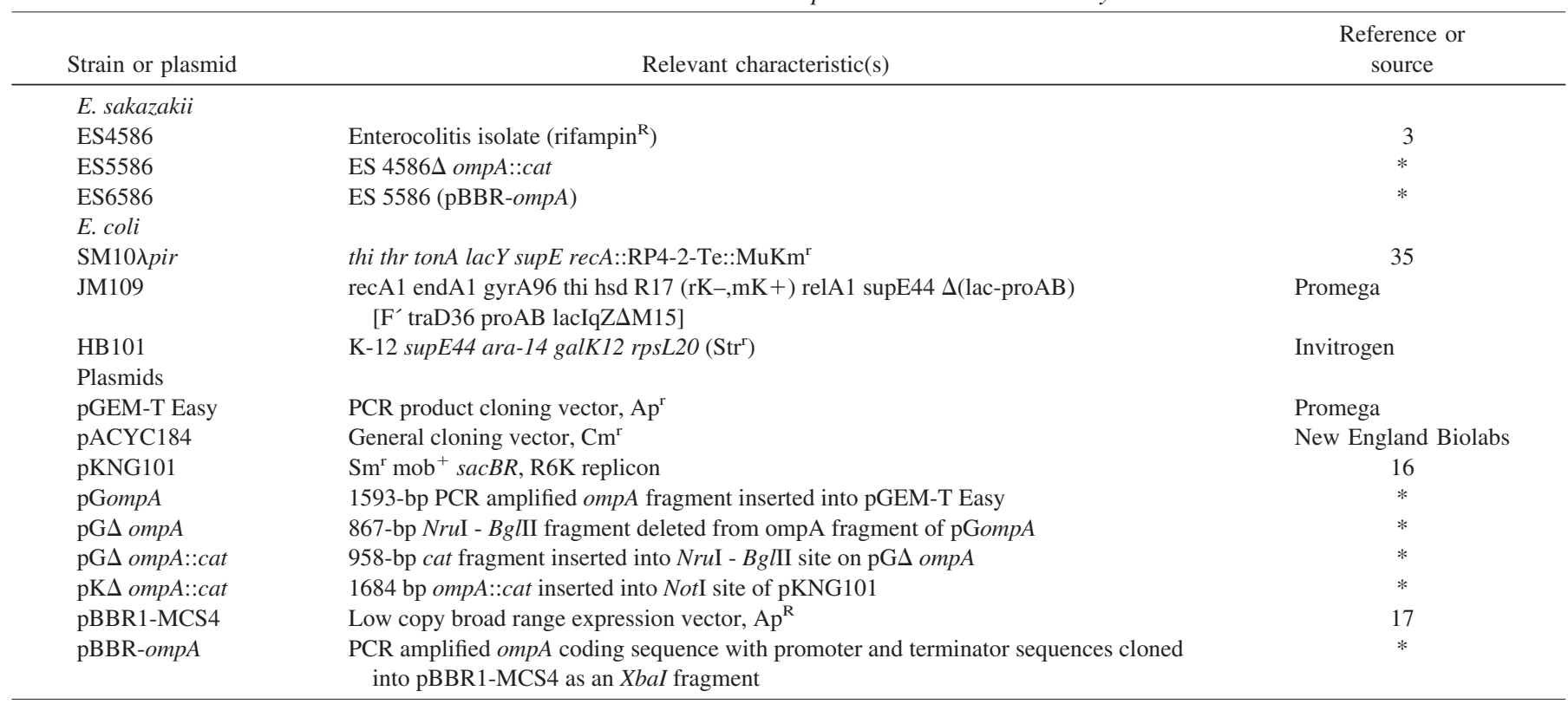

* This study.

For complementation, the ompA ORF along with the promoter and terminator sequences were amplified using primers OmpAORF-XbaF (5'GCGTCTAGAGCGATAGTGGTGAATGAACGG-3') and OmpAORFXbaR (5'-GCGTCTAGAGCGGAGCGTAAAGAGAAGTATG-3'), digested with $X b a \mathrm{I}$ and cloned in the low copy expression vector pBBR1-MCS4 (17). The resultant plasmid, pBBR-ompA was transformed into E. coli SM10 $\lambda$ pir and then mobilized to ES5586 ( $\mathrm{ompA}^{-}$) by conjugation. Expression of OmpA in the complemented strain (ES6586) was confirmed by Western blot using rabbit serum against E. coli OmpA (kind gift of Dr. Bruce Geller, Oregon State University, Corvallis, OR).

Outer membrane protein (OMP) extraction, SDS-PAGE, and Western blot. OMP were extracted from E. sakazakii strains by sodium sarcosinate treatment (18). One microgram of the OMP preparation from each strain was separated on $4 \%$ stacking-12\% resolving SDS-PAGE gels at $200 \mathrm{~V}$ for $1 \mathrm{~h}$ (19) and visualized by a modified silver stain protocol (20). For Western blot, proteins from the SDS-PAGE gels were transferred to nitrocellulose membranes at $350 \mathrm{~mA}$ for $1 \mathrm{~h} \mathrm{(21).} \mathrm{The} \mathrm{membranes} \mathrm{were} \mathrm{incubated} \mathrm{with} \mathrm{rabbit}$ anti-E. coli OmpA serum followed by peroxidase-labeled goat anti-rabbit immunoglobulin (Biomeda, Foster City, CA), and developed with $\alpha$-chloronaphthol (Sigma Chemical Co.-Aldrich, St. Louis, MO).

Binding and internalization of $\mathrm{E}$. sakazakii to human intestinal epithelial cells. Binding and internalization of E. sakazakii to intestinal epithelial cells were studied using INT407 cells [human embryonic intestine, ATCC, Manassas, VA; (22)]. Tissue culture trays (24-well) were seeded with $1.5 \times$ $10^{5}$ cells per well in Basal Medium Eagle (BME; Invitrogen, Grand Island, $\mathrm{NY}$ ) containing $10 \% \mathrm{FCS}$ at $37^{\circ} \mathrm{C}$ in a humidified and $5 \% \mathrm{CO}_{2}$ incubator for $24 \mathrm{~h}$. Monolayers were rinsed with BME and inoculated with bacterial suspension in BME-10\% FCS at different multiplicities of infection (MOI) ranging from 0.1 to 10,000 . The tissue culture trays were centrifuged at 600 $g$ for $5 \mathrm{~min}$, and incubated at $37^{\circ} \mathrm{C}$ for $2 \mathrm{~h}$. For binding assay, monolayers were rinsed five times with PBS, and lysed with $0.1 \%$ Triton X-100 for 15 min. The number of adherent cells was determined by serial dilution and plating of the suspension on tryptic soy agar. For internalization assay, the monolayers were rinsed three times in PBS and incubated for another $3 \mathrm{~h}$ in BME- $1 \%$ FCS containing gentamicin $(200 \mu \mathrm{g} / \mathrm{mL})$. The number of internalized bacteria was determined as described in the binding assay. Wild type (WT), omp $\mathrm{A}^{-}$, and complemented mutant strains were used for the study, and the percent invasion/binding was calculated using the formula (number of surviving bacteria divided by the number inoculated) $\times 100$. The assays were run in triplicate and replicated three times.

The role of fibronectin in the invasion of INT407 cells by E. sakazakii was analyzed by pretreating the monolayers with rabbit anti-human fibronectin serum (Biomeda) at $37^{\circ} \mathrm{C}$ for $30 \mathrm{~min}$, before inoculating with E. sakazakii. Monolayers incubated with rabbit preimmune serum served as controls.

Invasion in the presence of eukaryotic inhibitors. To study the role of eukaryotic cytoskeleton in E. sakazakii invasion of INT407 cells, invasion assays were performed in the presence of inhibitors of microfilaments (MF) and microtubules (MT) (Sigma Chemical Co.-Aldrich) (23). Cytochalasin D was incubated with INT407 cells for $30 \mathrm{~min}$ at $37^{\circ} \mathrm{C}$ and vinblastine and Taxol for $1 \mathrm{~h}$ at $37^{\circ} \mathrm{C}$, before addition of E. sakazakii. Colchicine and nocodazole were incubated with intestinal cells for $1 \mathrm{~h}$ at $4^{\circ} \mathrm{C}$ followed by 30 $\min$ at $37^{\circ} \mathrm{C}$ before infection.

Immunofluorescence. The role of the eukaryotic cytoskeleton in the invasive process of $E$. sakazakii was visualized by immunofluorescence staining and confocal microscopy (24). INT407 monolayers grown on 12-mm coverslips were infected with ES4586 as described above. The coverslips were fixed in $2 \%$ paraformaldehyde at room temperature for $15 \mathrm{~min}$ and permeabilized with $0.5 \%$ Triton X-100 in PBS containing $1 \%$ goat serum (Sigma Chemical Co.; PBSG) for 15 min. Actin was stained with TRITClabeled phalloidin (Sigma Chemical Co.; $0.5 \mu \mathrm{g} / \mathrm{mL}$ in PBSG, $1 \mathrm{~h}$ ) and tubulin with mouse anti $\alpha$-tubulin antibody (Sigma Chemical Co.; 1:1000 in PBSG, $1 \mathrm{~h}$ ) followed by TRITC-labeled goat anti-mouse immunoglobulin (Sigma Chemical Co.; 1:64 in PBSG, 1 h). E. sakazakii cells were stained with rabbit anti-OmpA serum (1:1000 in PBSG, $1 \mathrm{~h}$ ) followed by FITClabeled goat anti-rabbit serum for $1 \mathrm{~h}$. The coverslips were mounted on glass slides on Vectashield H-1000 (Vector Labs, Burlingame, CA) mounting medium, sealed with nail polish, and observed under a Leica true confocal scanner SP2 confocal microscope.

Statistical analysis. Data were expressed as mean values and SEM. For calculating the statistical significance $(p<0.05)$, two-tailed, unpaired $t$ test was used.

\section{RESULTS}

Invasion efficiency. The effect of the number of bacteria in the inoculum on the invasive process of E. sakazakii was monitored by assessing the percentage invasiveness and the number of internalized bacteria per well against over a wide range of MOI from 0.1 to 10,000 bacteria per INT407 cell. The percentage invasiveness was found to decrease with an increase in the MOI, and a maximum invasiveness of $0.36 \pm$ $0.06 \%$ was observed at an MOI of 0.1 , which declined sharply with an increase in MOI (Fig. 1A). In the MOI range of 1 to 100, ES4586 exhibited a percentage invasiveness ranging between $0.26 \pm 0.03$ and $0.08 \pm 0.002$. However, the noninvasive strain $E$. coli HB101 showed a significantly $(p<0.05)$ lower invasiveness (0.008-0.004) at the same MOI range.

In contrast to the percentage invasiveness, the number of internalized bacteria per well increased with an increase in 

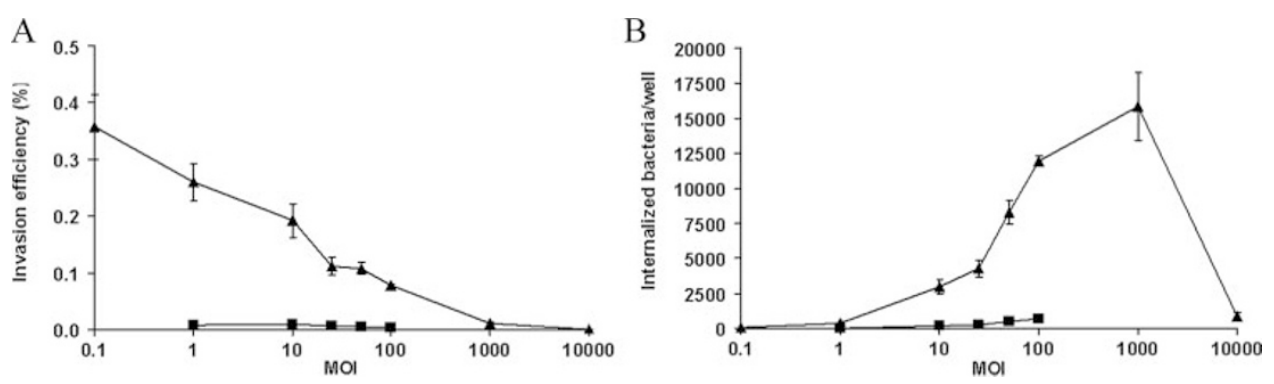

Figure 1. Effect of multiplicity of infection (MOI) on the invasive efficiency of $E$. sakazakii $(\mathbf{\Delta})$ and $E$. coli $\mathrm{HB} 101(\mathbf{\square})$ into INT407 cells expressed as $(A)$ percentage invasiveness or $(B)$ as the number of internalized bacteria per well (error bars indicate SE).

MOI from 0.1 to 1000 , followed by a sharp decline at a MOI of 10000 (Fig. 1B). The maximum number of E. sakazakii was internalized $(15,800 \pm 2,418)$ at a MOI of 1000 . The number of $E$. coli HB101 cells internalized remained significantly ( $p$ $<0.05)$ lower compared with ES4586 over a similar range of MOI. A MOI of 10,000 was found to produce rounding and detachment of a major portion of the monolayer from the wells, which could account for the sharp reduction in the number of internalized bacteria that was observed.

Effect of eukaryotic inhibitors on E. sakazakii invasion of Int407 cells. Role of MF. Cytochalasin D, an actin depolymerization agent was used to study the role of the actin cytoskeleton in E. sakazakii invasion. At the concentrations used, cytochalasin D caused rounding and retraction of epithelial cells without any detachment, and did not cause any significant changes in the viability of cells as evaluated by trypan blue staining (results not shown) compared with untreated controls. Cytochalasin D produced a dose dependent reduction in the invasiveness of $E$. sakazakii into INT407 cells (Fig. 2A) with approximately $93 \%$ inhibition observed at a concentration of $2 \mu \mathrm{M}$. Salmonella Typhimurium H3380 used as a positive control demonstrated $94 \%$ reduction in its invasiveness at the same concentration (Fig. $2 F$ ). However, the total number of bacteria associated with the epithelial cells did not vary significantly between the treated and untreated cells, indicating that the inhibitory effect is specifically at the level of invasion (results not shown).

Role of MT. The involvement of MT in E. sakazakii invasion was studied by conducting the invasion assays in the presence of different inhibitors of MT. Nocodazole, a MT depolymerization agent, produced a dose-dependent reduction in the invasiveness, which was not found to be statistically significant $(p>0.05)$ (Fig. $2 B$ ). At $20 \mu \mathrm{M}$, level nocodazole reduced $E$. sakazakii invasiveness by approximately $40 \%$. However, $10 \mu \mathrm{M}$ of each of the other two MT depolymerization agents, colchicine (Fig. 2C) and vinblastine (Fig. 2D), resulted in $40 \%$ and $72 \%$ reduction in E. sakazakii invasion, respectively $(p<0.05)$ compared with untreated controls. Similarly, the MT stabilizing agent, Taxol, at $20 \mu \mathrm{M}$ level produced $44 \%$ reduction in invasiveness ( $p<0.05$; Fig. $2 E$ ). All of these chemicals induced retraction and flattening of the epithelial cells without any detachment indicative of MT disruption, when viewed microscopically (results not shown). Similarly, none of these treatments caused any significant changes in the viability of epithelial cells as evaluated by trypan blue staining (results not shown) compared with untreated controls. Moreover, none of the inhibitors, at the greatest concentrations tested produced any significant reduction in S. Typhimurium invasiveness into INT407 cells (Fig. $2 F$ ). DMSO was used as a solvent for the cytoskeleton inhib-
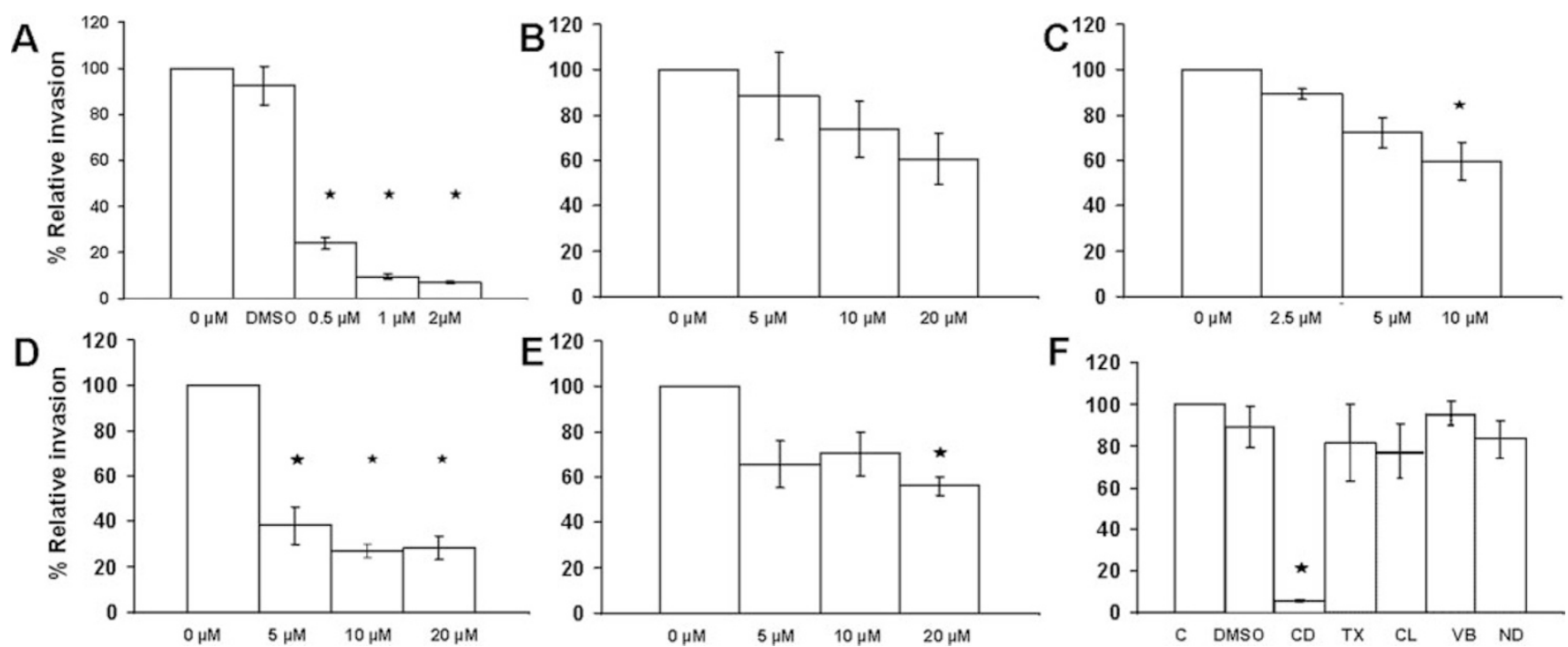

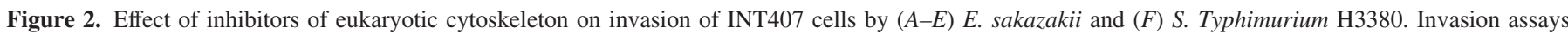

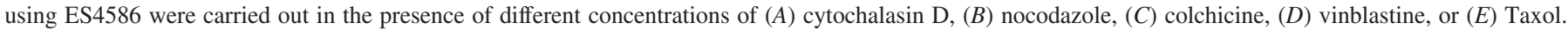

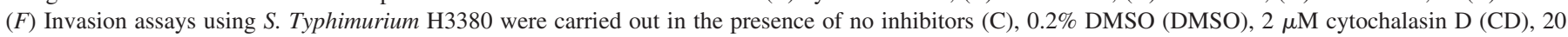
$\mu \mathrm{M}$ taxol (TX), $10 \mu \mathrm{M}$ colchicine (CL), $20 \mu \mathrm{M}$ vinblastine (VB), or $20 \mu \mathrm{M}$ Nocodazole (ND). Error bars indicate SE. $* p<0.05$. 
itors, which at $0.2 \%$ did not exert any significant effect on the invasiveness of E. sakazakii or S. Typhimurium.

Fluorescence staining of actin and tubulin. Confocal and epifluorescence microscopy were used to visualize bacteria and MF or MT in infected epithelial cells. Uninfected monolayers showed brightly stained cortical actin at the apical surface and a dense accumulation of thick long filaments (stress fibers) at the basal surface. Uninoculated cells treated with cytochalasin D exhibited complete dissolution of the stress fibers (results not shown). Monolayers observed at 30 and $60 \mathrm{~min}$ postinfection revealed the presence of bacteria attached in groups or in numbers ranging from one to a few to a subset of epithelial cells. Actin condensation was observed directly beneath the adherent bacteria in epithelial cells (Fig. $3, A$ and $B)$, although attached bacteria not associated with actin condensation was also observed. Intense fluorescence of actin condensation associated with attached bacterial cells was observed especially around the periphery of epithelial cells.

Similarly, E. sakazakii was found to interact with projections formed by bundles of MT extending from the epithelial cells (Fig. 4A) and E. sakazakii were found to co-localize with areas of MT polymerization in infected epithelial cells (Fig. 4, $B$ and $C$ ). However, not all the bacterial cells were found to be associated with MT polymerization and areas of intense tubulin staining not associated with attached bacterial cells were observed.

Role of fibronectin in invasion by E. sakazakii. Blocking the INT407 monolayers by incubation with rabbit anti-human fibronectin serum (1:100) for $30 \mathrm{~min}$ resulted in 47\% $(p<$ 0.05 ) reduction in the invasiveness of ES4586. Under similar
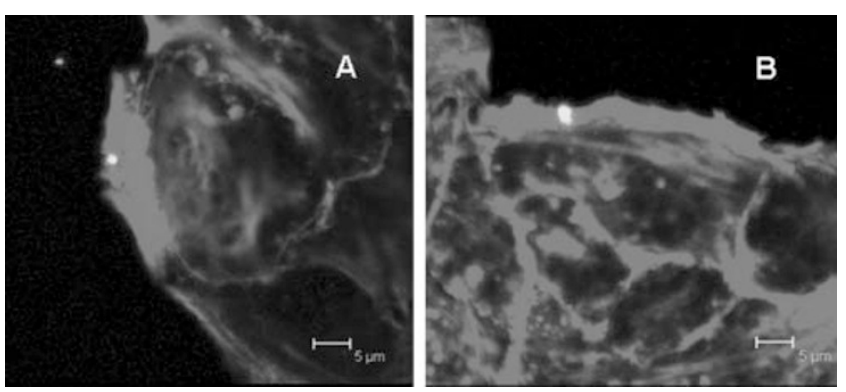

Figure 3. Representative confocal microscopic images of E. sakazakiiinfected INT407 cells showing bacterial interactions with MF. Shown are overlays of pixels of light derived from FITC (fluorescing bacteria) and TRITC (fluorescing actin filaments) filters.
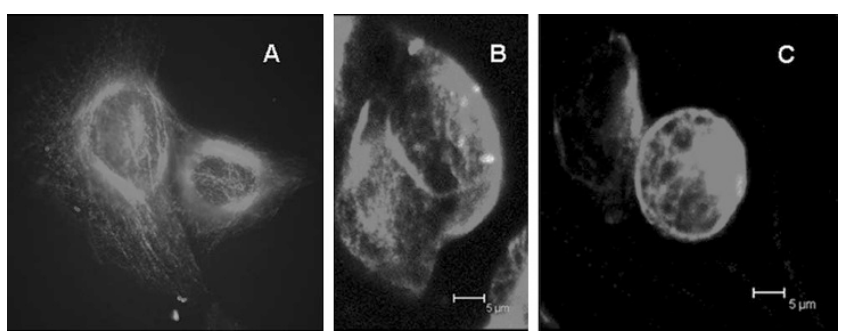

Figure 4. Representative $(A)$ epifluorescence and $(B, C)$ confocal microscopic images of $E$. sakazakii-infected INT407 cells showing bacterial interactions with MT. Shown are overlays of pixels of light derived from FITC (fluorescing bacteria) and TRITC (fluorescing tubulin filaments) filters. conditions, the invasiveness of the mutant strain declined by $28 \%(p>0.05)$. Incubation with preimmune rabbit serum (1:100) was found not to exert any significant effect on the invasiveness of both mutant and WT strains. Pretreatment of monolayers with anti-fibronectin serum resulted in a significant $(p<0.05)$ reduction in the percentage of cells adhering to the monolayer for both the WT and mutant strains (30\% and $33 \%$, respectively) compared with untreated controls (results not shown).

ompA mutation and complementation. The E. sakazakii ompA was mutated by replacing a gene fragment corresponding to the $\mathrm{N}$-terminus of the mature protein with a $\mathrm{cm}$ marker. PCR, Southern hybridization and nucleotide sequencing of the ompA region in the mutant strain revealed the internal deletion in the ompA gene and insertion of the $\mathrm{cm}$ marker at the point of deletion (results not shown). Further, SDS-PAGE and Western blot revealed lack of expression of an approximately $35 \mathrm{kD}$ protein in the mutant strain, that corresponds to the OmpA in the wild type (Fig. 5). However, the expression of OmpA was restored in the complemented strain, as observed in SDS-PAGE and Western blot profiles (Fig. 5).

Role of ompA in E. sakazakii invasion of int407 cells. The ability of the WT, mutant and complemented strains to invade INT407 cells was compared (Fig. 6) in a gentamicin protection assay, where the different strains were inoculated at a MOI of 10. The invasiveness of the mutant, expressed as percentage relative invasiveness, was only $13 \%$ of that of the WT $(p<0.05)$. However, complementation of the mutant with ompA significantly restored the invasive phenotype resulting in $64 \%$ invasiveness compared with the WT. Under similar conditions, there were no significant differences $(p>$ 0.05 ) in the total number of bacteria adhering to the monolayer between the WT, mutant, and complemented strains. This indicates that the reduced invasiveness of the mutant strain was a result of some defect in the invasive process rather than any failure of bacteria to associate with the monolayer. E. coli HB101, used as a negative control, was the least adhesive and invasive strain with $2 \%$ and $6 \%$ relative adhesiveness and invasiveness, respectively, compared with ES4586.

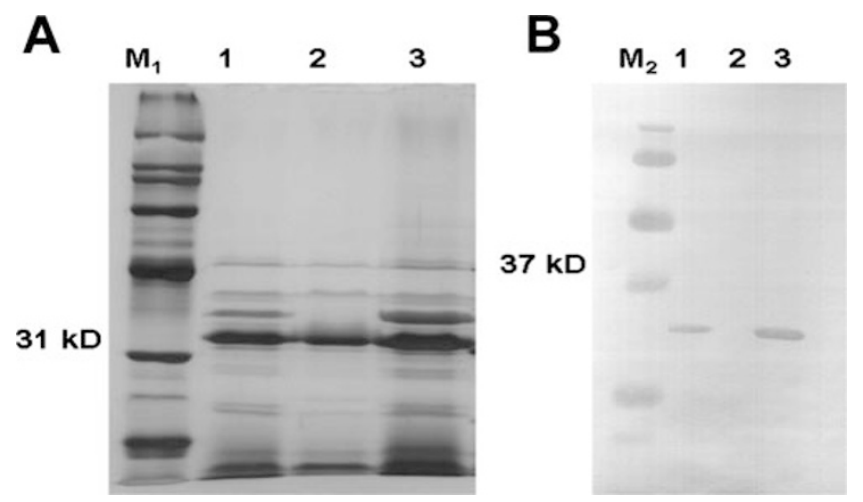

Figure 5. (A) SDS-PAGE and silver staining to detect OmpA expression. Lane $M_{1}$, broad range molecular weight standard; lane 1, ES4586 (WT); lane 2, ES5586 (ompA ${ }^{-}$); lane 3, ES6586 (complemented). (B) Western blot to detect OmpA expression. Lane $M_{2}$, prestained protein standard; lane 1, ES4586 (WT); lane 2, ES5586 (ompA -); lane 3, ES6586 (complemented). 


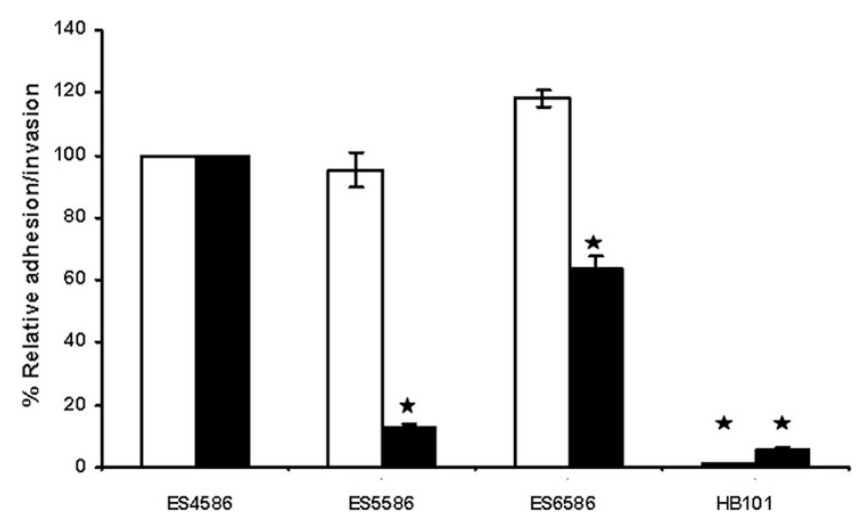

Figure 6. Percentage relative adhesion (white bars) and invasion (black bars) of ES4586 (WT), ES5586 (ompA-), ES6586 (complemented) and E. coli HB101 (negative control) strains into INT407 cells. Error bars indicate SE. $* p<0.05$.

\section{DISCUSSION}

E. sakazakii is an opportunistic pathogen causing intestinal and extraintestinal infections in susceptible infants and neonates. The pathogenesis of these infections remains elusive and very limited information is available on the virulence factors involved. Since this pathogen is known to enter the body through the oral route, we undertook this study to closely examine the interaction between E. sakazakii and human intestinal epithelial cells using a cell culture model. A second objective of this study was to investigate the contribution of $E$. sakazakii OmpA and host factors such as the actin and tubulin cytoskeleton in these interactions.

In our study, E. sakazakii was found to invade intestinal epithelial cells, albeit with a moderate efficiency. Invasion of host epithelial cells is a critical step in the pathogenesis of many bacterial infections. Highly invasive pathogens such as S. Typhi were reported to invade INT407 cells with an invasive efficiency up to $60 \%$ in $60 \mathrm{~min}$ (25), whereas for moderately invasive pathogens such as Campylobacter jejuni, invasion efficiencies between 0.1 and $0.4 \%$ were reported (24). The moderate invasiveness (approximately $0.2 \%$ ) of E. sakazakii observed is consistent with its pathogenic potential as an opportunistic pathogen. However, the invasiveness of E. sakazakii at a MOI of $10(0.192 \pm 0.029)$ was significantly greater (21-fold) than that of the noninvasive E. coli HB101 (0.0090 \pm 0.0012$)$. Invasion of intestinal cells could be an important step in the pathogenesis of intestinal infections and might aid in the translocation of E. sakazakii into the bloodstream from the intestinal tract, resulting in extra-intestinal infections such as sepsis and meningitis.

The exact role of fibronectin in the internalization process of E. sakazakii into intestinal epithelial cells is not clearly understood. Blocking fibronectin associated with the monolayer was found to significantly reduce both the total number of E. sakazakii attaching to the epithelial cells and invading them. Fibronectin-mediated binding could be a nonspecific first step where E. sakazakii comes in contact with the target cells, facilitating other specific interactions between bacterial ligands and host receptors. Alternatively, fibronectin could function as a bridge between a specific bacterial ligand and host cell receptor such as $\beta 1$-integrin, leading to internalization in specific cell types, as observed in S. aureus, S. pyogenes, and $N$. gonorrhoeae (11-13).

Our findings have identified that E. sakazakii OmpA plays an important role in the invasion of INT407 cells. In the absence of OmpA expression, the invasiveness of E. sakazakii declined by $87 \%$, whereas complementation of the mutant with ompA restored the invasiveness to $64 \%$ of that of the WT. However, the OmpA $\mathrm{A}^{-}$mutant did not significantly differ from the WT in its ability to adhere to the monolayer. Diffused adhesion of E. sakazakii to human epithelial and brain microvascular cells was inhibited by mannose, suggesting the presence of mannose sensitive type I fimbriae (26). Moreover, genes encoding the putative type I and curli fimbriae have been detected in E. sakazakii $(26,27)$. These and other yet unidentified surface determinants of E. sakazakii could also contribute to attachment to eukaryotic cells, making any potential OmpA-mediated adherence to host cells redundant.

Results of the present study clearly demonstrate that $E$. sakazakii invasion of INT407 cells involves participation of both MF and MT and bacterial OmpA plays a critical role in the invasion. Pathogens such as Salmonella, Listeria monocytogenes, Shigella flexneri, and Yersinia use an internalization pathway involving actin polymerization and the mechanisms behind their invasive processes are well understood (28). Pathogens such as N. gonorrhoeae and Klebsiella pneumoniae use uptake pathways that are both MF- and MT-dependent $(29,30)$. In our study, the effect of MF inhibition on INT407 invasion by $E$. sakazakii was found to be more pronounced compared with that of MT inhibition. A similar trend has been observed in bacterial pathogens such as K. pneumoniae and $E$. coli, where bacterial invasion of eukaryotic cells was more markedly inhibited by drugs acting on MF than those acting on MT $(30,31)$. This could be due to the existence of two independent pathways of internalization employing MF and MT simultaneously or due to the ability of MF to compensate the role of MT to some degree in the invasive process (30). Although the mechanisms behind MF-mediated bacterial internalization are fairly understood, the molecular basis of MT-dependant invasion is largely unknown. The effect of MT inhibitors could be an indirect effect on MF, as MT regulate the turn over of cells' focal adhesions, where the MF are cross-linked with membrane-associated adhesins (32). Alternatively, MT could be directly involved in E. sakazakii uptake or in intracellular trafficking or both. Inhibition of invasion by MT-stabilizing Taxol (which specifically blocks molecular motor such as dynein or kinesin-independent, MT pathway of internalization) (33) besides other MT-depolymerizers used, indicates that uptake through a direct MT-driven membrane invagination process is more likely. Further studies are required to elucidate the mechanisms behind involvement of MF and MT in E. sakazakii invasion. Similarly, the exact nature of interaction between OmpA and intestinal cells is not clear. $E$. sakazakii OmpA could function as a microbial ligand that up on interaction with a specific host receptor could trigger signaling events precipitating MF and/or MT rearrangements leading to bacterial internalization. OmpA of E. sakazakii shares a high level of sequence homology with that of E. coli, 
both at the nucleotide and the amino acid levels (15). Specific interactions between the surface-exposed domains of $E$. coli OmpA and host cell receptors have been shown to be critical for actin rearrangements and invasion into human brain endothelial cells (34). The possibility of similar interactions between E. sakazakii OmpA and receptors on INT407 cells needs to be investigated to fully characterize the mechanisms behind OmpA-mediated invasion of E. sakazakii into intestinal epithelial cells.

\section{REFERENCES}

1. Lai KK 2001 Enterobacter sakazakii infections among neonates, infants, children, and adults. Case reports and a review of the literature. Medicine (Baltimore) $80: 113-122$

2. Nazarowec-White M, Farber JM 1997 Incidence, survival, and growth of Enterobacter sakazakii in infant formula. J Food Prot 60:226-230

3. van Acker J, de Smet F, Muyldermans G, Bougatef A, Naessens A, Lauwers S 2001 Outbreak of necrotizing enterocolitis associated with Enterobacter sakazakii in powdered milk formula. J Clin Microbiol 39:293-297

4. Biering G, Karlsson S, Clark NC, Jonsdottir KE, Ludvigsson P, Steingrimsson O 1989 Three cases of neonatal meningitis caused by Enterobacter sakazakii in powdered milk. J Clin Microbiol 27:2054-2056

5. Bar-Oz B, Preminger A, Peleg O, Block C, Arad I 2001 Enterobacter sakazakii infection in the newborn. Acta Paediatr 90:356-358

6. Simmons BP, Gelfand MS, Haas M, Metts L, Ferguson J 1989 Enterobacter sakazakii infections in neonates associated with intrinsic contamination of a powdered infant formula. Infect Control Hosp Epidemiol 10:398-401

7. Center for Disease Control and Prevention (CDC) 2002 Enterobacter sakazakii infections associated with the use of powdered infant formula-Tennessee, 2001. MMWR Morb Mortal Wkly Rep 51:297-300

8. FSNET 8 November 2002 Recalled baby formula found in Colorado stores. Colorado Department of Public Health and Environment press release. Retrieved from http:// archives.foodsafetynetwork.ca/fsnet/2002/11-2002/fsnet_november_8-2.htm\# RECALLED\%20BABY. Accessed on June 19, 2007

9. Pagotto FJ, Nazarowec-White M, Bidawid S, Farber JM 2003 Enterobacter sakazakii: infectivity and enterotoxin production in vitro and in vivo. J Food Prot 66:370-375

10. Gilot P, André P, Content J 1999 Listeria monocytogenes possesses adhesins for fibronectin. Infect Immun 67:6698-6701

11. Molinari G, Talay SR, Valentin-Weigand P, Rohde M, Chhatwal GS 1997 The fibronectin-binding protein of Streptococcus pyogenes, SfbI, is involved in the internalization of group A streptococci by epithelial cells. Infect Immun 65:13571363

12. van Putten JP, Duensing TD, Cole RL 1998 Entry of OpaA+ gonococci into HEp-2 cells requires concerted action of glycosaminoglycans, fibronectin and integrin receptors. Mol Microbiol 29:369-379

13. Massey RC, Kantzanou MN, Fowler T, Day NP, Schofield K, Wann ER, Berendt AR, Hook M, Peacock SJ 2001 Fibronectin-binding protein A of Staphylococcus aureus has multiple, substituting, binding regions that mediate adherence to fibronectin and invasion of endothelial cells. Cell Microbiol 3:839-851

14. Sambrook J, Fritsch EF, Maniatis T 1989 Molecular Cloning: A Laboratory Manual, 2nd ed., Cold Spring Harbor, NY
15. Mohan Nair MK, Venkitanarayanan KS 2006 Cloning and sequencing of ompA gene of Enterobacter sakazakii and development of an ompA-targeted PCR for rapid detection of Enterobacter sakazakii in infant formula. Appl Environ Microbiol 72:2539-2546

16. Kaniga K, Delor I, Cornelis GR 1991 A wide-host-range suicide vector for improving reverse genetics in Gram-negative bacteria: inactivation of the blaA gene of Yersinia enterocolitica. Gene 109:137-141

17. Kovach ME, Elzer PH, Hill DS, Robertson GT, Farris MA, Roop RM 2nd, Peterson KM 1995 Four new derivatives of the broad-host-range cloning vector pBBR1MCS, carrying different antibiotic-resistance cassettes. Gene 166:175-176

18. Blaser MJ, Hopkins JA, Berka RM, Vasil ML, Wang WL 1983 Identification and characterization of Campylobacter jejuni outer membrane proteins. Infect Immun 42:276-284

19. Laemmli UK 1970 Cleavage of structural proteins during the assembly of the head of bacteriophage T4. Nature 227:680-685

20. Rabilloud T, Carpentier G, Tarroux P 1988 Improvement and simplification of low-background silver staining of proteins by using sodium dithionite. Electrophoresis 9:288-291

21. Towbin H, Staehelin T, Gordon J 1979 Electrophoretic transfer of proteins from polyacrylamide gels to nitrocellulose sheets: procedure and some applications. Proc Natl Acad Sci U S A 76:4350-4354

22. Monteville MR, Yoon JE, Konkel ME 2003 Maximal adherence and invasion of INT407 cells by Campylobacter jejuni requires the CadF outer-membrane protein and microfilament reorganization. Microbiology 149:153-165

23. Prasadarao NV, Wass CA, Stins MF, Shimada H, Kim KS 1999 Outer membrane protein A-promoted actin condensation of brain microvascular endothelial cells is required for Escherichia coli invasion. Infect Immun 67:5775-5783

24. Biswas D, Itoh K, Sasakawa C 2003 Role of microfilaments and microtubules in the invasion of INT-407 cells by Campylobacter jejuni. Microbiol Immunol 47:469-473

25. Huang XZ, Tall B, Schwan WR, Kopecko DJ 1998 Physical limitations on Salmonella typhi entry into cultured human intestinal epithelial cells. Infect Immun 66:2928-2937

26. Mange JP, Stephan R, Borel N, Wild P, Kim KS, Pospischil A Lehner A 2006 Adhesive properties of Enterobacter sakazakii to human epithelial and brain microvascular endothelial cells. BMC Microbiol 6:58

27. Zogaj X, Bokranz W, Nimtz M, Romling U 2003 Production of cellulose and curli fimbriae by members of the family Enterobacteriaceae isolated from the human gastrointestinal tract. Infect Immun 71:4151-4158

28. Rottner K, Lommel S, Wehland J, Stradal TE 2004 Pathogen-induced actin filament rearrangement in infectious diseases. J Pathol 204:396-406

29. Grassme HU, Ireland RM, van Putten JP 1996 Gonococcal opacity protein promotes bacterial entry-associated rearrangements of the epithelial cell actin cytoskeleton. Infect Immun 64:1621-1630

30. Oelschlaeger TA, Tall BD 1997 Invasion of cultured human epithelial cells by Klebsiella pneumoniae isolated from the urinary tract. Infect Immun 65:2950-2958

31. Oelschlaeger TA, Barrett TJ, Kopecko DJ 1994 Some structures and processes of human epithelial cells involved in the uptake of enterohemorrhagic Escherichia coli O157:H7 strains. Infect Immun 62:5142-5150

32. Ballestrem C, Wehrle-Haller B, Hinz B, Imhof BA 2000 Actin-dependent lamellipodia formation and microtubule-dependent tail retraction control-directed cell migration. Mol Biol Cell 11:2999-3012

33. Hertle R, Schwarz H 2004 Serratia marcescens internalization and replication in human bladder epithelial cells. BMC Infect Dis 4:16

34. Prasadarao NV 2002 Identification of Escherichia coli outer membrane protein A receptor on human brain microvascular endothelial cells. Infect Immun 70:45564563

35. Wang Y, Kim KS 2002 Role of OmpA and IbeB in Escherichia coli $\mathrm{K} 1$ invasion of brain microvascular endothelial cells in vitro and in vivo. Pediatr Res 51:559-563 